\title{
Mechanical properties and temperature stability of modified polybutylene terephthalate by beta rays
}

\author{
Ales Mizera ${ }^{1, a}$, Miroslav Manas ${ }^{1}$, David Manas ${ }^{1}$, Pavel Stoklasek ${ }^{1}$, Martin Bednarik ${ }^{1}$ and Lenka Hylova ${ }^{1}$ \\ ${ }^{1}$ Tomas Bata University in Zlin, nam. T. G. Masaryka 5555, 76001 Zlin, Czech Republic
}

\begin{abstract}
The presented article deals with the research of mechanical properties before and after temperature load and temperature stability of modified polybutylene terephthalate by radiation cross-linking. The mechanical properties were measured, at the ambient temperature, by the tensile test on samples which were non-irradiated and irradiated by different doses of the beta radiation and then were temperature loaded. Results demonstrate that PBT has higher values of tensile strength with the increased irradiation dose and it has decreased elongation at break sharply. The purpose of the article is to consider to what extent the irradiation process influences the resulting mechanical properties and temperature stability. The PBT tested showed significant improvement of temperature stability after irradiation. This behaviour leads to the expansion of these materials in the automotive and electrical industry.
\end{abstract}

\section{Introduction}

Radiation processing of polymers is a well-established and economical commercial method of precisely modifying the polymer properties. The industrial applications of the radiation processing of plastics and composites include polymerization, cross-linking, degradation and grafting. Radiation processing mainly involves the use of either electron beams from electron accelerators or gamma radiation from Cobalt-60 sources $[1,2]$.

During the last few decades the industrial use of radiation crosslinking for polymers have rapidly increased. Radiation cross-linking cause a noticeable improvement in the properties of polymers, e.g. their mechanical, chemical and thermal properties [3]. The electron beam radiation process is practically free of waste products and therefore is no serious environmental hazard. The main difference between beta and gamma rays is in their different abilities to penetrate the irradiated material. Gamma rays have a high penetration capacity. The penetration capacity of electron rays depends on the energy of the accelerated electrons. Due to electron accelerators, the required dosage can be applied within seconds, whereas several hours are required in the gamma radiation plant $[1,2]$.

As a result, we can optimise properties of commodity and engineering polymers and impart them the properties of high performance polymers. Irradiation of polymers turned out to be interesting because of economic reasons, production costs and a life time of products. However, these benefits depend on the type of irradiated polymer and the radiation dosage. Behaviour of each material is different after irradiation. We cannot expect the improvement in all areas (mechanical, thermal and chemical). Most of polymers are not suitable for irradiation because of degradation and deterioration of their properties [4].

Radiation processing of polymers involves treatment of polymer materials with ionizing radiation to modify their physical and chemical properties to make property improvement. Therefore, using of ionizing radiation has found a very wide range of applications in medicine, agriculture and industry. Many scientists have examined the issues of polymer radiation cross-linking. They discovered that some of polymer materials exposed to the ionizing radiation tend to either improve or worsen their mechanical properties. It depends on chemical structure if polymers cross-link or degrade predominantly. Degradation is an undesirable process which may cause significant deterioration of crucial properties for some applications. Effect of radiation cross-linking significantly improves temperature stability. Because of that, materials which belong to group of commodity polymers can be used in applications, which would be in term of temperature stability intended only to engineering thermoplastic polymers $[5,6,7,8]$.

Beta radiation is used for irradiation of PBT in this research. Although many research papers are written about radiation cross-linking of numerous of polymers [9, $10,11]$, not so many research papers are written about irradiation of polybutylene terephthalate. A small amount of research which is written about radiation cross-linking of polybutylene terephthalate is written $[12,13]$ but it does not examine mechanical properties and thermal resistance. These research papers study dielectric constant, thermal degradation and flames retardant additives [12], the effect of gamma irradiation on

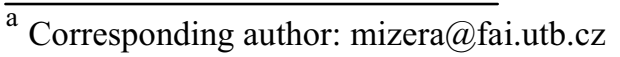


dielectric surface breakdown of PBT under reduced pressure [13].

This research paper deals with a possibility of using radiation cross-linked PBT as a suitable material for automotive industry, especially from point of temperature stability.

\section{Experimental}

As the basic polymer material was used polybutylene terephthalate (PBT, V-PTS-CREATEC-B3HZC*M800/ 125 natur). An ARBURG Allrounder 420C Advance Injection molding machine was used for sample preparation, with the processing conditional to comply with the PBT producer's recommendations.

Irradiation of tested PBT was performed with the kind help of BGS Germany, in the BGS Wiehl plant using accelerated electrons with a dosage range of 0 to 198 $\mathrm{kGy}$. Then samples were exposed temperature $200{ }^{\circ} \mathrm{C}$ during one hour and after that these samples were cooled spontaneously to ambient temperature.

Mechanical properties before and after temperature load and temperature stability of irradiated polybutylene terephthalate after irradiation has been tested. The thermo-mechanical properties were measured. Perkin Elmer Thermal Analyser TMA7 was used for the thermomechanical analysis, heated from $50{ }^{\circ} \mathrm{C}$ to $400{ }^{\circ} \mathrm{C}$ at 20 ${ }^{\circ} \mathrm{C} / \mathrm{min}$, hold for $1 \mathrm{~min}$ at $50{ }^{\circ} \mathrm{C}$. The tensile behaviour of temperature non-loaded and loaded samples of PBT were measured at the ambient temperature. Tensile test was carried out on tensile test machine ZWICK 1456 for PBT according to standard CSN EN ISO 527-1, 527-2 with used rate $50 \mathrm{~mm} / \mathrm{min}$. Test data was processed by Test Expert Standard software and E-modulus [MPa], tensile strength $[\mathrm{MPa}]$ and elongation [\%] were determined.

\section{Results and discussion}

\subsection{Temperature stability}

Temperature stability of polymers is very low in comparison with other construction materials. Experiments done in this project show that irradiation cross-linking markedly affects the temperature stability of studied PBT. The higher is the dose of irradiation the best is temperature stability of this polymers.

The temperature stability of PBT was measured. The temperature stability was evaluated by TMA measurement and by visual observation. The graphical depiction of TMA results and description of a test record of the temperature stability inside a temperature chamber are described the dose of radiation from 0 to $198 \mathrm{kGy}$. Irradiation affects the thermo-mechanical properties of the studied PBT (Figure 1). Non-irradiated and irradiated PBT sample with the dose of irradiation $33 \mathrm{kGy}$ are melted at the temperature $230^{\circ} \mathrm{C}$. PBT with the increased dose above $132 \mathrm{kGy}$ is not lost the temperature stability up to $300{ }^{\circ} \mathrm{C}$. Irradiated PBT specimens above the dose of irradiation $132 \mathrm{kGy}$ evince the significant improvement of temperature stability.
The visual observation of sample behaviour after one hour exposition at $250{ }^{\circ} \mathrm{C}$ is given on Figure 2 . Specimens are fitted horizontally in the temperature chamber and loaded by the bending moment both form its own weight and the weight on the end of specimen. Specimen deformation is decreasing with increasing dose of radiation at elevated temperature. At $250{ }^{\circ} \mathrm{C}$ the specimen from not irradiated PBT is totally melted while the polymer irradiated by the dose of $198 \mathrm{kGy}$ keeps its cross-section without changes, there is only deformation by its own weight. The surface quality worsens and the colour of polymer specimen change due to thermooxidation.

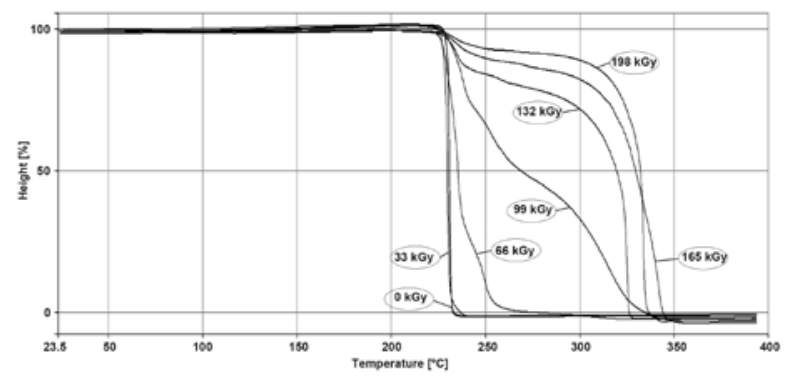

Figure 1. PBT thermomechanical analysis.

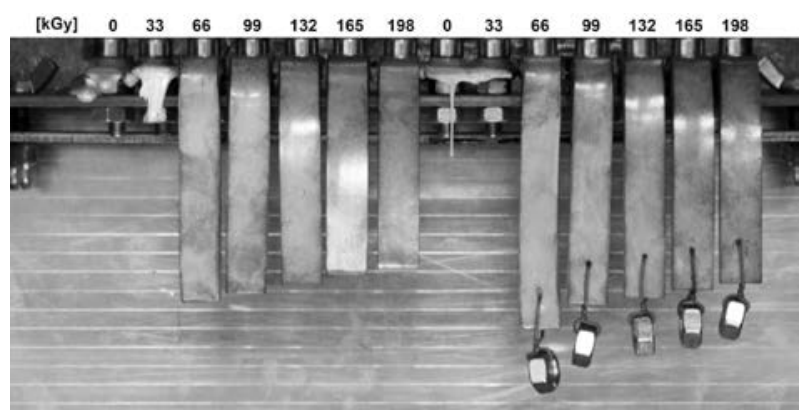

Figure 2. PBT visual observation at $250{ }^{\circ} \mathrm{C}$.

On Figure 3 hot penetration test is displayed at temperature $250{ }^{\circ} \mathrm{C}$. Change of colours is not visible, however, on Figure 4, in the centre of penetration there is beginning of termo-oxidative degradation at $300{ }^{\circ} \mathrm{C}$.

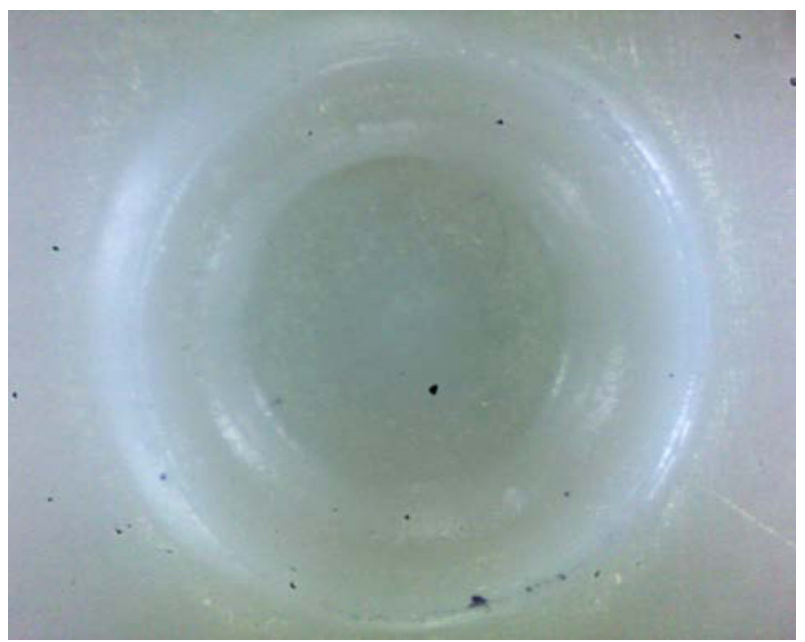

Figure 3. 100 times magnified indentation mark into irradiated PBT by $132 \mathrm{kGy}$ after 5 seconds of penetration at $250{ }^{\circ} \mathrm{C}$.

The surface quality worsens and the colour of polymer specimen change due to thermo-oxidation more and more with increasing temperature as it can be seen on 
Figure 5 and 6. It was observed that another irradiated PBT samples changed colours with increasing temperature almost the same as at $132 \mathrm{kGy}$.

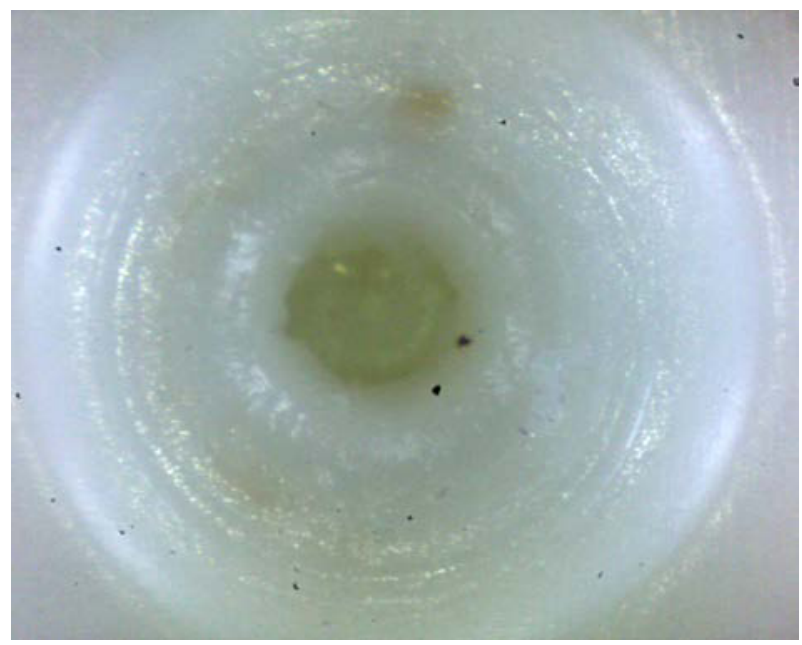

Figure 4. 100 times magnified indentation mark into irradiated PBT by $132 \mathrm{kGy}$ after 5 seconds of penetration at $300{ }^{\circ} \mathrm{C}$.

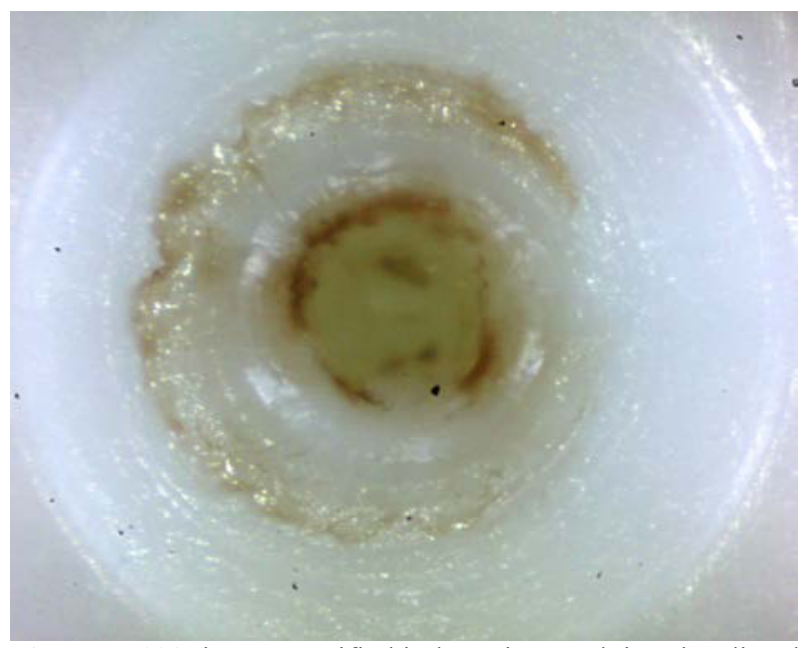

Figure 5. 100 times magnified indentation mark into irradiated PBT by $132 \mathrm{kGy}$ after 5 seconds of penetration at $350{ }^{\circ} \mathrm{C}$.

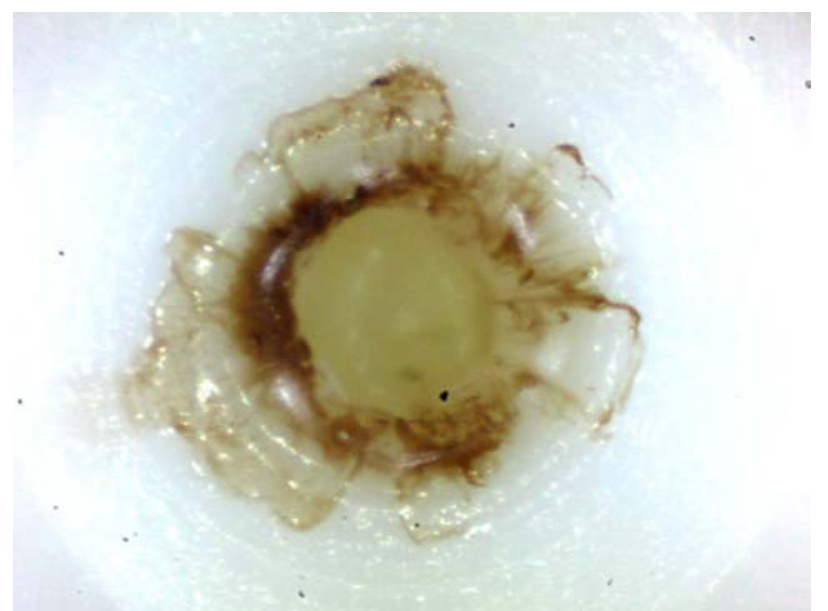

Figure 6. 100 times magnified indentation mark into irradiated PBT by $132 \mathrm{kGy}$ after 5 seconds of penetration at $400{ }^{\circ} \mathrm{C}$.

\subsection{Tensile behaviour}

The tensile behaviour of PBT, before and after irradiation, was studied. For easier of evaluation of the measured data, and the comparison of the irradiated polymer with a non-irradiated one, the changes of measured were used on some graphs. The property of the non-irradiated polymer had the value of $100 \%$, while others were expressed in $\%$ as the ratio of measured property of irradiated polymers to the same property of non-irradiated polymer.

After performing the tensile test at ambient $\left(23^{\circ} \mathrm{C}\right)$ temperature the observed parameter (E-modulus) was compared. As can be seen from Figure 7, there was a significant growth of the E-modulus with increasing doses of irradiation. It was a progressive increase from $1703 \mathrm{MPa}$ to $2022 \mathrm{MPa}$ and from $1989 \mathrm{MPa}$ to 2149 $\mathrm{MPa}$ for temperature loaded PBT at the dose of irradiation $198 \mathrm{kGy}$. The E-modulus rises by 19 and $27 \%$ after irradiation with a dosage of $198 \mathrm{kGy}$ in comparison with non-irradiated PBT.

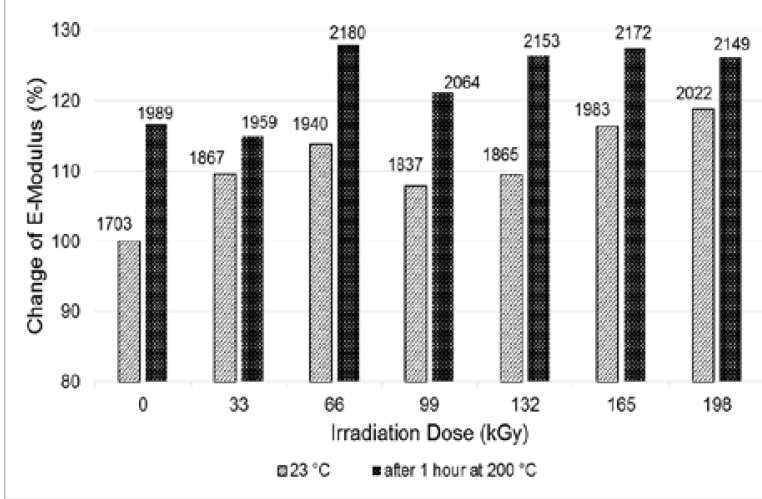

Figure 7. Change of E-modulus before and after temperature load.

After performing the tensile test at ambient $\left(23^{\circ} \mathrm{C}\right)$ temperature the observed parameter (tensile strength) was compared. As can be seen from Figure 8, there was a significant growth of the tensile strength with increasing doses of irradiation up to $132 \mathrm{kGy}$ then tensile strength is almost constant with increasing dose of irradiation for both types of measurement. The tensile strength rises by 7.1 and 3.2 MPa for temperature non-loaded and loaded PBT, respectively, after irradiation with a dosage of 198 $\mathrm{kGy}$ in comparison with non-modified PBT.

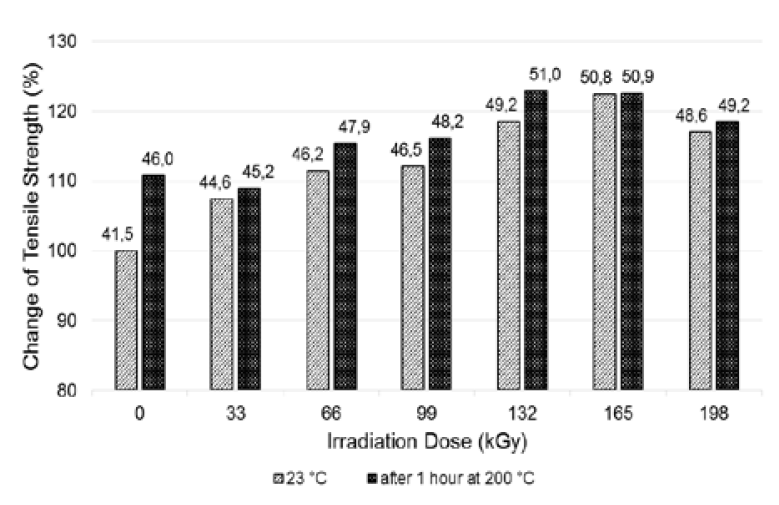

Figure 8. Change of tensile strength before and after temperature load. 
After performing the tensile test at ambient $\left(23^{\circ} \mathrm{C}\right)$ temperature the observed parameter (elongation at break) was compared. As can be seen from Figure 9, there was a significant decline of the elongation at break with increasing doses of irradiation and also with temperature load. It was a sharp decrease from $119 \%$ to $17 \%$ at the dose of irradiation $66 \mathrm{kGy}$ then the elongation at break was almost constant. The elongation at break decreases by $80 \%$ after temperature load at $200{ }^{\circ} \mathrm{C}$ in comparison with non-modified PBT.

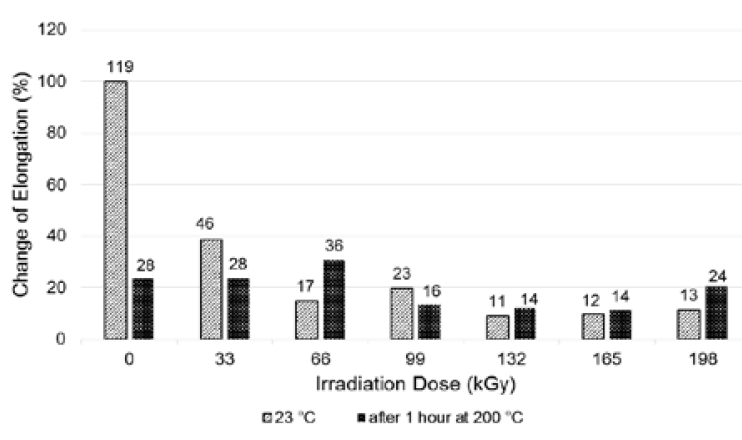

Figure 9. Change of elongation at break before and after temperature load.

\section{Summary}

Plastics are by far the largest group of polymeric materials being processed by electron beam irradiation. Cross-linking of polyolefins, PVC, polyesters, polyurethanes, polyamides, fluoropolymers and fiberreinforced composites are a common practice. Radiation cross-linking of polyamides requires considerably less overall energy and space, and is faster, more efficient and more environmentally acceptable. The disadvantage of electron beam cross-linking is a more or less nonuniform dose distribution. This can happen, particularly in thicker objects, due to intrinsic dose-depth profiles of electron beams. Another problem can be a nonuniformity of rotation of cylindrical objects as they traverse a scanned electron beam. However, the mechanical properties often depend on the mean cross-link density [1].

The temperature stability of polymers is very low in comparison with other construction materials. Experiments done in this project showed that irradiation cross-linking markedly affected the temperature stability of the PBT studied. The higher the irradiation dosage, the better the temperature stability of studied polymers is. As can be seen from the tests results, the irradiation crosslinking improves the PBT tensile behaviour. The improvement is more considerable in case of higher temperature $\left(200{ }^{\circ} \mathrm{C}\right)$, as a consequence of creation of cross-link (during irradiation cross-linking) resulting in protraction of macromolecular chain, which is thus more flexible during thermal load than individual shorter macromolecular chains.

As can be seen from the tests results, the irradiation cross-linking improves the PBT tensile behaviour. The results of the measurements of PBT after irradiation showed significant changes of tensile strength, E- modulus and elongation at break. The tensile strength rises by $23 \%$, after irradiation with a dosage of $165 \mathrm{kGy}$ at the both temperatures $\left(23\right.$ and $\left.200{ }^{\circ} \mathrm{C}\right)$. The E-modulus rises by 19 and $27 \%$, after irradiation with a dosage of $198 \mathrm{kGy}$ at the ambient and elevated temperature, respectively. The elongation at break decreases by $80 \%$ after temperature load at $200{ }^{\circ} \mathrm{C}$ in comparison with nonmodified PBT.

A very important point is the improvement of the PBT specimens' temperature stability, after irradiation. The tested polymer, when irradiated by a dosage of $198 \mathrm{kGy}$ showed no dimensional changes - even at a temperature of $250^{\circ} \mathrm{C}$. This significantly moves the application possibilities of the PBT specimens we tested to an area with service temperatures much higher than their former melting-point. However, this study dealt with PBT material only, hence more polymer materials and a wider range of temperature will be investigated to confirm or deny these findings.

\section{Acknowledgment}

This paper is supported by the internal grant of TBU in Zlin No. IGA/FT/2016/010 funded from the resources of specific university research and by the Ministry of Education, Youth and Sports of the Czech Republic within the National Sustainability Programme project No. LO1303 (MSMT-7778/2014) and also by the European Regional Development Fund under the project CEBIATech No. CZ.1.05/2.1.00/03.0089.

\section{References}

1. K. Makuuchi, S. Cheng, Radiation Processing of Polymer Materials and Its Industrial Applications (Wiley, Hoboken, 2011)

2. J.G. Drobny, Ionizing Radiation and Polymers: Principles, Technology and Applications (Elsevier, Oxford, 2013)

3. Joachim Gehring, Radiat. Phys. Chem. 57, 361 (2000)

4. Z. Holik at al., Chem. Listy 105(S), 269-271 (2011)

5. D.W. Clegg, A.A. Collyer, Irradiation effects on polymers (Elsevier Applied Science, London, 1991)

6. J.G. Drobny, Radiation Technology for Polymers (CRC Press, Boca Raton, 2003)

7. R.L. Clough, S.W. Shalaby, Irradiation of Polymers: Fundamentals and Technological Applications (American Chemical Society, 1996)

8. H.A. Khonakdar et al., Indian J. Chem. Tech. 75, 78 (2006)

9. D. Manas, M. Hribova, M. Manas, M. Ovsik, M. Stanek, D. Samek, Thin Solid Films 530, 49 (2013)

10. S. Nakamura, K. Tokumitsu, T. Yamaguchi, J. Appl. Polym. Sci. 130, 4318 (2013)

11. J. Chen, M. Czayka, R.M. Uribe, Radiat. Phys. Chem. 74, 31 (2005)

12. Z. Hooshangi, S.A.H. Feghhi, N. Sheikh, Radiat. Phys. Chem. 108, 54 (2015)

13. B.X. Du, H.J. Liu, Y. Liu, IEEE Transactions on Dielectrics and Electrical Insulation 14, 696 (2006) 